\title{
Obstructive voiding symptoms following stereotactic body radiation therapy for prostate cancer
}

\author{
W Tristram Arscott ${ }^{1 \dagger}$, Leonard N Chen $^{1+}$, Nathan Wilson ${ }^{1}$, Aditi Bhagat ${ }^{1}$, Joy S Kim', Rudy A Moures ${ }^{1}$, \\ Thomas M Yung ${ }^{1}$, Siyuan Lei ${ }^{1}$, Brian T Collins' ${ }^{1}$ Keith Kowalczyk², Simeng Suy ${ }^{1}$, Anatoly Dritschilo', \\ John H Lynch ${ }^{2}$ and Sean P Collins ${ }^{1 *}$
}

\begin{abstract}
Background: Obstructive voiding symptoms (OVS) are common following prostate cancer treatment with radiation therapy. The risk of urinary retention (UR) following hypofractionated radiotherapy has yet to be fully elucidated. This study sought to evaluate OVS and UR requiring catheterization following SBRT for prostate cancer.

Methods: Patients treated with SBRT for localized prostate cancer from February 2008 to July 2011 at Georgetown University were included in this study. Treatment was delivered using the CyberKnife ${ }^{\circledR}$ with doses of 35 Gy-36.25 Gy in 5 fractions. UR was prospectively scored using the CTCAE v.3. Patient-reported OVS were assessed using the IPSS-obstructive subdomain at baseline and at 1, 3, 6, 9, 12, 18 and 24 months. Associated bother was evaluated via the EPIC-26.

Results: 269 patients at a median age of 69 years received SBRT with a median follow-up of 3 years. The mean prostate volume was $39 \mathrm{cc}$. Prior to treatment, $50.6 \%$ of patients reported moderate to severe lower urinary track symptoms per the IPSS and 6.7\% felt that weak urine stream and/or incomplete emptying were a moderate to big problem. The 2-year actuarial incidence rates of acute and late UR $\geq$ grade 2 were $39.5 \%$ and $41.4 \%$. Alpha-antagonist utilization rose at one month (58\%) and 18 months (48\%) post-treatment. However, Grade 3 UR was low with only 4 men (1.5\%) requiring catheterization and/or TURP. A mean baseline IPSS-obstructive score of 3.6 significantly increased to 5.0 at 1 month $(p<0.0001)$; however, it returned to baseline in $92.6 \%$ within a median time of 3 months. Late increases in OVS were common, but transient. Only $7.1 \%$ of patients felt that weak urine stream and/or incomplete emptying was a moderate to big problem at two years post-SBRT $(p=0.6854)$.

Conclusions: SBRT treatment caused an acute increase in OVS which peaked within the first month post-treatment, though acute UR requiring catheterization was rare. OVS returned to baseline in $>90 \%$ of patients within a median time of three months. Transient Late increases in OVS were common. However, less than $10 \%$ of patients felt that OVS were a moderate to big problem at two years post-SBRT.
\end{abstract}

Keywords: Prostate cancer, SBRT, CyberKnife, IPSS, Retention, Catheterization, TURP

\footnotetext{
* Correspondence: SPC9@gunet.georgetown.edu

'Equal contributors

'Department of Radiation Medicine, Georgetown University Hospital, 3800

Reservoir Road, NW, Washington, DC 20007, USA

Full list of author information is available at the end of the article
} 


\section{Background}

Benign prostatic hyperplasia $(\mathrm{BPH})$ and related lower urinary tract symptoms (LUTS) are a common problem of male aging [1]. LUTS consists of both irritative and obstructive voiding symptoms [1,2]. In men greater than seventy years old, the prevalence of LUTS may be as high as $30 \%$ [3]. Older age [4], non-Caucasian race [5], comorbidities [6], and obesity [5] may increase the risk of LUTS.

Obstructive voiding symptoms commonly occur following external beam radiation therapy (EBRT) for prostate cancer and may adversely affect a patient's quality of life $[7,8]$. The cause of these symptoms may involve prostatic edema, however the etiology is not fully understood [9-11]. Patients report incomplete emptying, intermittency, weak stream and straining [2], which develop days to weeks after the start of treatment and generally resolve weeks to months following completion of EBRT [12-15]. Patient characteristics including prostatic volume [14,16,17], IPSS score [11,17-19], BPH [20], and prior procedures for $\mathrm{BPH}[19,21]$ may contribute to an individual's risk of radiation-induced UR [22]. Pre-treatment androgen deprivation therapy (ADT) $[23,24]$ and/or posttreatment alpha agonists $[25,26]$ may decrease treatmentrelated symptoms.

Brachytherapy is an effective and convenient treatment option for clinically localized prostate cancer [27-30]. Obstructive voiding symptoms are the primary urinary morbidity following brachytherapy. Treatment-related factors such as physician experience [31,32], isotope selection $[33,34]$ and/or the number of needle applicators utilized $[35,36]$ may affect the incidence and severity of obstructive voiding symptoms. Acute urinary retention (AUR) is common and may occur in $5-20 \%$ of patients [31]. In some cases, prolonged catheterization and/or transurethral resection of the prostate (TURP) are required, which increase the risk of long term urinary incontinence [37]. Intraoperative image-optimized delivery may reduce, but not eliminate, urinary toxicity [38,39]. The negative impact of AUR on quality of life (QoL) is high and lasts for years after the catheter has been removed [40].

Stereotactic Body Radiation Therapy (SBRT) is a safe and effective treatment for clinically localized prostate cancer [41-45]. The larger dose per fraction untilized in SBRT offers the potential radiobiological benefits of hypofractionation [46]. Initial reports suggest that the incidence of urinary obstruction following SBRT is comparable to other external radiotherapy modalities, and may be less than brachytherapy [41-43]. The goal of this study is to report the incidence and prevalence of obstructive voiding symptoms and urinary retention following SBRT for clinically localized prostate cancer.

\section{Methods}

\section{Patient selection}

Georgetown University Hospital established its Prostate SBRT Program in 2006. As of December 2013, 700 prostate cancer patients have been treated with SBRT plus or minus supplemental external beam radiation therapy. At the inception of our program, a prospective database was established to record baseline patient characteristics. At each follow-up visit, toxicity and quality of life data have also been prospectively collected and recorded. Patients eligible for this study were those who had SBRT monotherapy for clinically localized prostate cancer and a minimum of two years of follow-up. Internal Review Board (IRB) approval was obtained for retrospective review of our database.

\section{SBRT treatment planning and delivery}

SBRT treatment planning and delivery were conducted as previously described $[47,48]$. Briefly, four to six stranded gold fiducials (1013- 2-2, Best Medical International, Inc., Springfield, VA, USA) were placed into the prostate with two to three needle applicators via a trans-rectal or transperineal approach. Fused computed tomography $(\mathrm{CT})$ and magnetic resonance magnetic resonance (MR) images were used for treatment planning. The clinical target volume (CTV) included the prostate and the proximal seminal vesicles. The planning target volume (PTV) equaled the CTV expanded $3 \mathrm{~mm}$ posteriorly and $5 \mathrm{~mm}$ in all other dimensions. The prescription dose was 35-36.25 Gy to the PTV delivered in five fractions of 7-7.25 Gy over one to two weeks. The prescription isodose line was limited to $\geq 75 \%$, which limited the maximum prostatic urethra dose to $133 \%$ of the prescription dose. The membranous urethra was contoured and evaluated with dose-volume histogram analysis during treatment planning using Multiplan (Accuray Inc., Sunnyvale, CA). The dose-volume histogram (DVH) goal was for $<50 \%$ membranous urethra to receive $37 \mathrm{~Gy}$. To minimize the risk of local recurrence, the dose to the prostatic urethra was not constrained [49]. Prostate position was verified during treatment using paired, orthogonal x-ray images [50].

\section{Follow-up and statistical analysis}

Toxicity and quality of life data were obtained before treatment and during routine follow-up visits every 3 months for the first year and every six months for the second year. Alpha-antagonist utilization was documented at each visit. Physician-reported toxicity was prospectively documented at follow-up visits using the National Cancer Institute (NCI) Common Toxicity Criteria (CTC) version 3.0. Toxicity that occurred between assessments was assigned to the later time point. For example, if a toxicity occurred one week after SBRT it was recorded at one month post-SBRT. Acute toxicity 
was defined as experiencing toxicity within 6 months of SBRT and late toxicity was defined as occurring greater than 6 months after delivery of SBRT. Grade 1 urinary retention consisted of dribbling or hesitancy not requiring medications for symptom control. Grade 2 urinary retention indicates hesitancy requiring new medication (i.e. alpha-antagonist) or increase in dose of previously prescribed medication. Urinary retention requiring catheterization and/or transurethral resection of the prostate was scored as Grade 3.

Patient-reported obstructive voiding symptoms were assessed via the International Prostate Symptom Score (IPSS), a validated questionnaire where higher scores indicate more severe symptoms [2]. The recall period for the IPSS is one month [51]. The IPSS includes four question related to obstructive symptoms (incomplete emptying, intermittency, weak stream and straining). For each IPSS obstructive question, the responses were grouped into four clinically relevant categories (never, $<1 / 2$ time, $\geq 1 / 2$ time and always). The IPSS obstructive subscore (IPSS-O) has been previously defined as the sum of the scores for questions 1, 3, 5, and 6 [52]. Overall IPSS-O scores ranged from 0 - 20. IPSS-0 resolution was defined as a return to within one point of the baseline score [13]. Bother with obstructive urinary symptoms was assessed via Question $4 \mathrm{~d}$ of the Expanded Prostate Index Composite (EPIC)-26 ("How big a problem, if any, has weak urine stream or incomplete emptying been for you during the last four weeks?") [53] for which responses were grouped into three clinically relevant categories (no problem, small problem and moderate to big problem).

Student's $t$-test and Wilcoxon signed-rank test were used to assess differences in ongoing toxicity and quality of life scores in comparison to baseline. Sample medians and ranges were used to describe continuous variables. Actuarial likelihood estimates for late urinary retention $\geq$ grade 2 and time to IPSS-O resolution were determined using the Kaplan-Meier method. To statistically compare changes between time points, the levels of responses were assigned a score and the significance of the mean changes in the scores was assessed by paired $t$ test. The minimally important difference (MID) in IPSS-O score was defined as a change of one-half standard deviation (SD) from the baseline [54]. To limit the effect of attrition bias, statistical analysis was limited to time points in which $\geq 80 \%$ of the patient data were available.

\section{Results}

From February 2008 to July 2011, 269 prostate cancer patients were treated per our institutional SBRT monotherapy protocol (Table 1) with a median follow-up of 3 years. They were ethnically diverse with a median age of 69 years (range, 44-90 years). The median prostate volume was $39 \mathrm{cc}$ and $10 \%$ had prior procedures for
Table 1 Baseline patient characteristics and treatment

\begin{tabular}{|c|c|c|}
\hline & & $\begin{array}{c}\text { \% Patients } \\
(\mathrm{N}=269)\end{array}$ \\
\hline \multirow[t]{5}{*}{ Age (y/o) } & Median 69 (44-90) & \\
\hline & $<60$ & $8.2 \%$ \\
\hline & $60-69$ & $42.4 \%$ \\
\hline & $70-79$ & $41.3 \%$ \\
\hline & $\geq 80$ & $8.2 \%$ \\
\hline \multicolumn{3}{|l|}{ Race } \\
\hline & White & $55.8 \%$ \\
\hline & Black & $37.2 \%$ \\
\hline & Other & $7.1 \%$ \\
\hline Baseline PSA (ng/dL) & Median $6.2(0.2-32.5)$ & \\
\hline Prostate Volume (cc) & Median 39.04 (11.56-138.69) & \\
\hline \multirow[t]{4}{*}{ IPSS Baseline } & Median 8 (0-33) & \\
\hline & Mild $(\leq 7)$ & $49.3 \%$ \\
\hline & Moderate (8-19) & $45.5 \%$ \\
\hline & Severe $(\geq 20)$ & $5.2 \%$ \\
\hline \multicolumn{3}{|c|}{ Procedure for BPH prior to RT } \\
\hline & Yes & $10.0 \%$ \\
\hline & No & $90.0 \%$ \\
\hline \multicolumn{3}{|c|}{$a_{1 \mathrm{~A}}$ Antagonist Utilization } \\
\hline & Yes & $32.1 \%$ \\
\hline & No & $67.9 \%$ \\
\hline \multicolumn{3}{|l|}{ Risk Group } \\
\hline & Low & $36.8 \%$ \\
\hline & Intermediate & $53.2 \%$ \\
\hline & High & $10.0 \%$ \\
\hline \multicolumn{3}{|l|}{ Hormonal Therapy } \\
\hline & Yes & $16.4 \%$ \\
\hline & No & $83.6 \%$ \\
\hline \multicolumn{3}{|l|}{ Dose } \\
\hline & 36.25 Gy & $83.3 \%$ \\
\hline & $35 \mathrm{~Gy}$ & $16.4 \%$ \\
\hline & Other & $0.4 \%$ \\
\hline
\end{tabular}

BPH including simple prostatectomy (1 patient), TURP (10 patients), TUNA (1 patient) and TUMT (7 patients).

The median baseline IPSS was 8 , and $32 \%$ of patients were using alpha-antagonists prior to SBRT. One patient utilized intermittent catheterization prior to treatment. By D'Amico classification, 99 patients were low-, 143 intermediate-, and 27 high-risk. Sixteen percent of patients received androgen deprivation therapy (ADT) via a gonadotropin-releasing hormone agonist for a median duration of 3 months (range, 3-24 months). Eighty three percent of patients were treated with 36.25 Gy in five 7.25 Gy fractions. 
Table 2 Prevalence of CTC graded urinary retention at each follow-up

\begin{tabular}{lccccccc}
\hline & $\mathbf{1}$ Mon & $\mathbf{3}$ Mon & $\mathbf{6}$ Mon & $\mathbf{9}$ Mon & $\mathbf{1 2}$ Mon & $\mathbf{1 8}$ Mon & $\mathbf{2 4}$ Mon \\
\hline Grade 0 & $41.7 \%$ & $57.7 \%$ & $55.0 \%$ & $58.7 \%$ & $56.2 \%$ & $54.5 \%$ & $55.4 \%$ \\
Grade 1 & $21.6 \%$ & $16.6 \%$ & $20.7 \%$ & $19.0 \%$ & $18.7 \%$ & $19.3 \%$ & $21.2 \%$ \\
Grade 2 & $36.7 \%$ & $25.7 \%$ & $23.9 \%$ & $21.9 \%$ & $25.1 \%$ & $25.8 \%$ & $23.0 \%$ \\
Grade 3 & $0.0 \%$ & $0.0 \%$ & $0.4 \%$ & $0.4 \%$ & $0.0 \%$ & $0.4 \%$ & $0.5 \%$ \\
\hline
\end{tabular}

The prevalence of urinary retention following treatment is shown in Table 2. The corresponding 2-year actuarial incidence of acute and late UR $\geq$ grade 2 was $39.5 \%$ and $41.4 \%$, respectively (Figure $1 \mathrm{~A}$ ). Alphaantagonist use rose at one month (57.9\%) and 18 months (48.0\%) post-treatment (Figure 1B). However, Grade 3 UR was low with only 4 men (1.5\%) requiring catheterization and/or TURP.

The majority of patients had obstructive voiding symptoms prior to treatment with a mean baseline IPSS-O score of 3.7 (Table 3, Figure 2A). At one month postSBRT, the mean IPSS-O significantly increased to 5.0 $(p<0.0001)$, but returned to baseline at 3 months $(p=0.74$, Figure 2A). This increase was of borderline clinical significance $(\mathrm{MID}=1.8)$. The median time to IPSS-O normalization was 3 months (Figure 2B). The IPSS-O returned to baseline in $79.6 \%$ of patients by 6 months and $92.6 \%$ by 2 years (Figure 2B). Late IPSS-O increases were common, but transient (Figure 2A). Individual obstructive voiding symptoms (incomplete emptying, intermittency, weak stream and straining) followed a similar trend (Table 4).

At baseline, $44.9 \%$ of our cohort reported some level of bother due to weak stream and/or incomplete emptying with $6.7 \%$ of patients feeling it was a moderate to big problem (Table 5, Figure 3). At one month post-SBRT, moderate to big bother with obstructive voiding symptoms increased to $10.4 \%(p<0.0001)$, but reduced to
$5.1 \%$ at 3 months $(p=0.79)$. Although bother declined quickly, a second late transient increase in bother occurred at one year (Table 5, Figure 3). However, only $7.1 \%$ of patients felt that weak urine stream and/or incomplete emptying was a moderate to big problem at two years post-SBRT $(p=0.6854)$.

\section{Discussion}

Obstructive voiding symptoms following prostate cancer radiotherapy are common and an important quality of life issue [7]. A better understanding of the pattern of obstructive voiding symptoms following SBRT will enable clinicians to provide more realistic expectations to patients [55]. In this study, we utilized validated QoL questionnaires to comprehensively evaluate obstructive voiding symptoms following SBRT [2,53].

An increase in obstructive voiding symptoms is a common response to prostate radiotherapy. This study shows that SBRT acutely increases all obstructive voiding symptoms (incomplete emptying, intermittency, weak stream and straining) in a similar manner. The 2-year actuarial incidence rates of acute and late UR $\geq$ grade 2 in this series were $39.5 \%$ and $41.4 \%$, respectively. New alpha-antagonist use or alpha-antagonist dose increase were the most common indications of grade 2 toxicities. It is our institutional policy to proscribe alpha-antagonists for mild to moderate LUTS, and this may explain the high rate of $\mathrm{GU}$ toxicity $\geq$ grade 2 seen in this study [47].
(A)

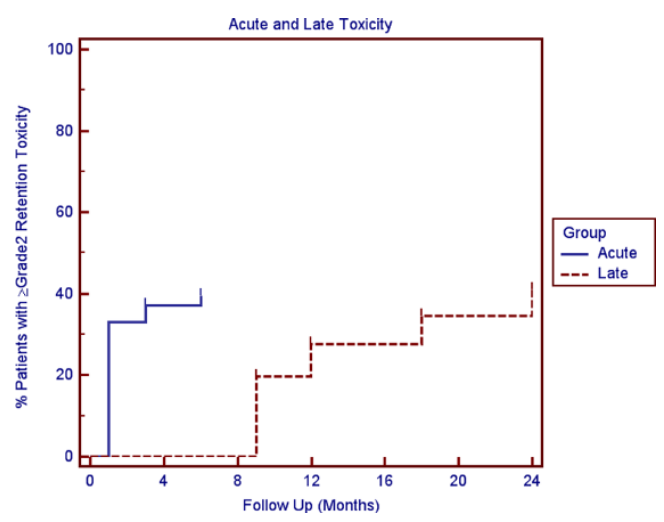

(B)

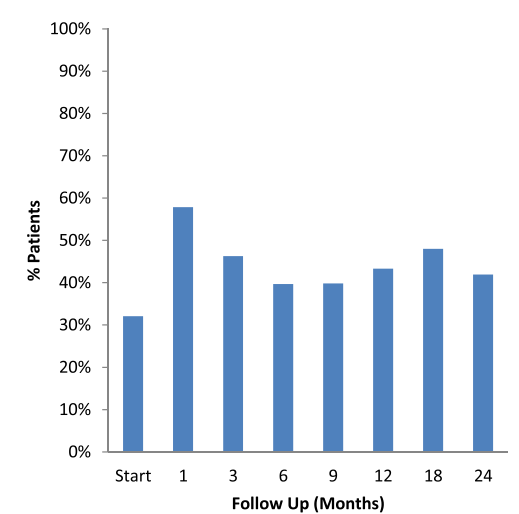

Figure 1 Acute and late grade 2 urinary retention. (A) Cumulative acute ( $\leq 6$ months post-RT) and late ( $>6$ months post-RT) urinary retention $\geq$ grade 2 . (B) Proportion of patients utilizing $a_{1 A}$ antagonists at each time point. 
Table 3 Changes in IPSS-O scores following SBRT for prostate cancer

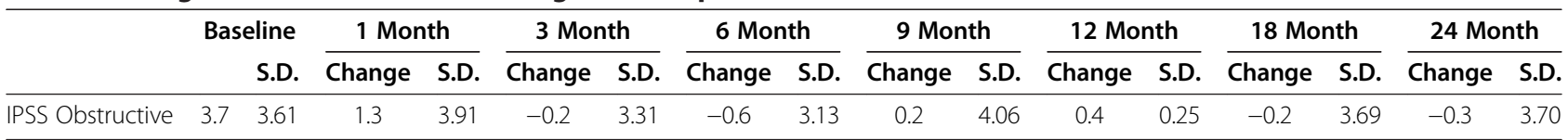

S.D., standard deviation.

Nonetheless, our results appear similar to those reported for IMRT [56] and brachytherapy [31]. To maximize patient comfort, it is currently our institutional policy to initiate prophylactic alpha antagonist use [57] and to treat on an every other day schedule [58].

Post-SBRT urinary symptoms may be exacerbated by high radiation doses to the center of the prostate [47]. With the aim of reducing urinary symptoms, we have modified our institutional protocol. Specifically, we have reduced the anterior/superior PTV expansion to reduce the bladder neck dose. In addition, it is now our practice to prescribe to $\geq 80 \%$ isodose line to reduce the central hot spot that may involve the prostatic urethra. We believe that such modifications will reduce the incidence and severity of urinary symptoms.

Due to its effectiveness and convenience, brachytherapy is a common treatment option for prostate cancer. Post-implant UR is a common (5-20\%) toxicity that may impact long-term quality of life. Risk factors for postimplant UR include large prostate volume, high pretreatment IPSS score and BPH. Our patients were old with poor baseline urinary function, yet the incidence of UR following SBRT in this series was low $(<5 \%)$. This low incidence was possibly due to limited needle trauma and/or the use of neoadjuvant ADT in patients with large prostate volumes and high pretreatment IPSS scores [24]. Because of the limited number of events, this study could not determine risk factors for UR following SBRT. If cancer control is similar, SBRT may be a convenient treatment option for patients at high risk of UR following brachytherapy [14,19].

IPSS resolution following brachytherapy varies from months to years $[13,15,31]$. As seen in other SBRT series [41], our mean IPSS scores returned to baseline within three months post-SBRT. A minority of patients experienced a transient increase in obstructive voiding symptoms greater than six months after the completion of SBRT. As with brachytherapy, late urinary symptom flare [59-61] occurred in a minority of our patients and resolved with conservative management. Knowledge of this late increase in obstructive voiding symptoms and their resolution with conservative management will enable clinicians to address patient concerns and prevent unnecessary catheterization and/or TURP.

Bother is defined as the degree of interference or annoyance caused by a symptom $[15,62]$. Similar to other radiation modalities, bother with weak stream and/or incomplete voiding plateaued within the first month following treatment with $10 \%$ of men reporting a moderate to big problem. This change compares favorably to that reported at two months with conventionally fractionated external beam radiation therapy (23\%) and brachytherapy $(40 \%)$ [7]. As see with external beam radiation therapy, this increase in bother was transient and returned to baseline by 3 months post-SBRT. A second increase in bother occurred 12 months post-SBRT with $11 \%$ of patients reporting moderate to big bother at this time point. This change is comparable to that reported at
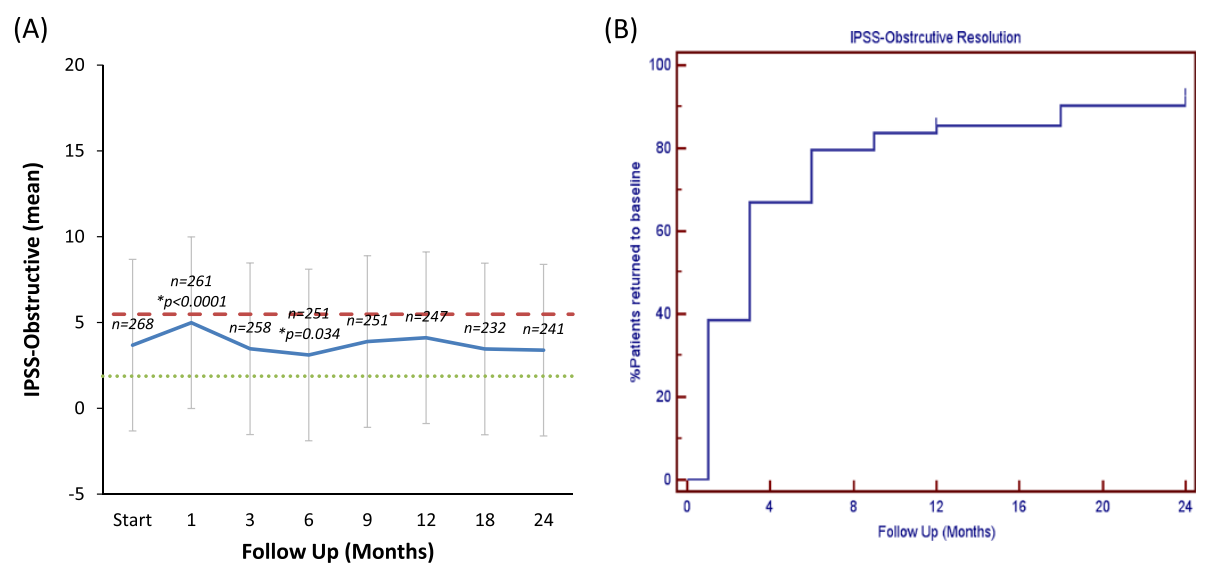

Figure 2 Obstructive voiding symptoms following SBRT for prostate cancer. (A) Mean IPSS-O score. The graphs show unadjusted changes in average scores over time. IPSS-O scores range from 0-20 with higher values representing worsening obstructive voiding symptoms. The thresholds for clinically significant changes in scores ( $1 \frac{1}{2}$ standard deviation above and below the baseline) are marked with dashed lines. Error bars indicate $95 \%$ confidence intervals. (B) Time to IPSS-O resolution (return to within one point of the baseline score). 
Table 4 Obstructive voiding symptoms following SBRT for prostate cancer: patient-reported responses to IPSS questions 1 (incomplete emptying), 3 (intermittency), 5 (weak stream) and 6 (straining)

\begin{tabular}{|c|c|c|c|c|c|c|c|c|c|}
\hline & & Start & 1 Mon & 3 Mon & 6 Mon & 9 Mon & 12 Mon & 18 Mon & 24 Mon \\
\hline \multicolumn{10}{|c|}{ Incomplete Voiding } \\
\hline Never & & $45.1 \%$ & $26.8 \%$ & $36.6 \%$ & $45.6 \%$ & $40.4 \%$ & $37.8 \%$ & $42.9 \%$ & $44.1 \%$ \\
\hline$<1 / 2$ times & & $42.2 \%$ & $52.5 \%$ & $53.7 \%$ & $47.2 \%$ & $45.2 \%$ & $46.7 \%$ & $46.0 \%$ & $43.3 \%$ \\
\hline$<1 / 2$ times & & $11.2 \%$ & $18.0 \%$ & $7.4 \%$ & $6.8 \%$ & $12.0 \%$ & $14.6 \%$ & $8.8 \%$ & $8.8 \%$ \\
\hline Always & & $2.6 \%$ & $2.7 \%$ & $2.7 \%$ & $1.2 \%$ & $3.2 \%$ & $1.6 \%$ & $3.1 \%$ & $4.2 \%$ \\
\hline & $p$ & & $<0.0001$ & 0.747 & 0.1302 & 0.5017 & 0.2546 & 0.5802 & 0.7787 \\
\hline \multicolumn{10}{|c|}{ Intermittency } \\
\hline Never & & $45.9 \%$ & $33.3 \%$ & $45.1 \%$ & $50.0 \%$ & $45.2 \%$ & $43.5 \%$ & $51.3 \%$ & $50.8 \%$ \\
\hline$<1 / 2$ times & & $40.3 \%$ & $51.0 \%$ & $47.5 \%$ & $42.4 \%$ & $43.6 \%$ & $39.4 \%$ & $37.2 \%$ & $39.1 \%$ \\
\hline$<1 / 2$ times & & $12.3 \%$ & $13.4 \%$ & $5.1 \%$ & $6.8 \%$ & $9.2 \%$ & $15.4 \%$ & $9.7 \%$ & $9.2 \%$ \\
\hline Always & & $1.5 \%$ & $2.3 \%$ & $2.3 \%$ & $0.8 \%$ & $2.0 \%$ & $1.6 \%$ & $1.8 \%$ & $0.8 \%$ \\
\hline & $p$ & & 0.0025 & 0.1411 & 0.0156 & 0.7464 & 0.8765 & 0.1081 & 0.0225 \\
\hline \multicolumn{10}{|c|}{ Weak Stream } \\
\hline Never & & $42.7 \%$ & $26.8 \%$ & $37.7 \%$ & $42.8 \%$ & $37.2 \%$ & $34.1 \%$ & $41.2 \%$ & $40.3 \%$ \\
\hline$<1 / 2$ times & & $40.8 \%$ & $46.7 \%$ & $48.6 \%$ & $42.0 \%$ & $43.2 \%$ & $48.0 \%$ & $41.6 \%$ & $45.4 \%$ \\
\hline$<1 / 2$ times & & $11.2 \%$ & $22.6 \%$ & $10.9 \%$ & $13.2 \%$ & $16.8 \%$ & $13.4 \%$ & $12.8 \%$ & $10.9 \%$ \\
\hline Always & & $5.2 \%$ & $3.8 \%$ & $2.7 \%$ & $2.0 \%$ & $2.8 \%$ & $4.5 \%$ & $4.4 \%$ & $3.4 \%$ \\
\hline & $p$ & & $<0.0001$ & 0.9055 & 0.6035 & 0.1365 & 0.1183 & 0.7275 & 0.6782 \\
\hline \multicolumn{10}{|l|}{ Straining } \\
\hline Never & & $72.4 \%$ & $60.2 \%$ & $74.3 \%$ & $73.9 \%$ & $68.4 \%$ & $65.0 \%$ & $72.4 \%$ & $75.6 \%$ \\
\hline$<1 / 2$ times & & $24.6 \%$ & $33.3 \%$ & $22.6 \%$ & $23.7 \%$ & $25.6 \%$ & $29.3 \%$ & $24.4 \%$ & $20.6 \%$ \\
\hline$<1 / 2$ times & & $1.9 \%$ & $5.7 \%$ & $2.7 \%$ & $2.4 \%$ & $4.8 \%$ & $5.3 \%$ & $3.1 \%$ & $3.4 \%$ \\
\hline \multirow[t]{2}{*}{ Always } & & $1.1 \%$ & $0.8 \%$ & $0.4 \%$ & $0.0 \%$ & $1.2 \%$ & $0.4 \%$ & $0.4 \%$ & $0.4 \%$ \\
\hline & $p$ & & 0.0001 & 0.7224 & 0.2286 & 0.1191 & 0.0482 & 0.7608 & 0.3241 \\
\hline
\end{tabular}

12 months with intensity modulated radiation therapy (15\%) [8], proton therapy (11\%) [8] and brachytherapy (18\%) [7]. Unlike brachytherapy, though, bother following SBRT returned to near baseline by two years.

Our study has several limitations. There was a poor correlation between physician-reported toxicity and patientreported outcomes. The prescription of an alpha-antagonist for obstructive urinary symptoms was not guided by a standard protocol [12]. It is possible, that many patients with mild obstructive urinary symptoms received alphaantagonists and were inappropriately scored a Grade 2 toxicity. Alternatively, the high rate of alpha-antagonist utilization in this study may have hidden the true incidence of patient reported obstructive voiding symptoms with SBRT. In addition, most late obstructive voiding symptoms were transient and associated bother may have been missed due to the timing of questionnaire administration [51].

Table 5 Bother from weak urine stream and/or incomplete emptying following SBRT for prostate cancer (patient-reported responses to question $4 d$ of the EPIC-26)

\begin{tabular}{|c|c|c|c|c|c|c|c|c|}
\hline & Start & 1 Mon & 3 Mon & 6 Mon & 9 Mon & 12 Mon & 18 Mon & 24 Mon \\
\hline No Problem & $55.1 \%$ & $38.2 \%$ & $53.9 \%$ & $53.2 \%$ & $52.6 \%$ & $49.0 \%$ & $55.1 \%$ & $55.6 \%$ \\
\hline Very small-small problem & $38.2 \%$ & $51.4 \%$ & $41.0 \%$ & $42.8 \%$ & $39.4 \%$ & $39.6 \%$ & $38.2 \%$ & $37.2 \%$ \\
\hline Moderate-big problem & $6.7 \%$ & $10.4 \%$ & $5.1 \%$ & $4.0 \%$ & $8.0 \%$ & $11.4 \%$ & $6.7 \%$ & $7.1 \%$ \\
\hline$N=$ & 267 & 259 & 256 & 250 & 249 & 245 & 225 & 239 \\
\hline$p$ & & $<0.0001$ & 0.795994 & 0.841946 & 0.197648 & 0.021191 & 1 & 0.68536 \\
\hline
\end{tabular}




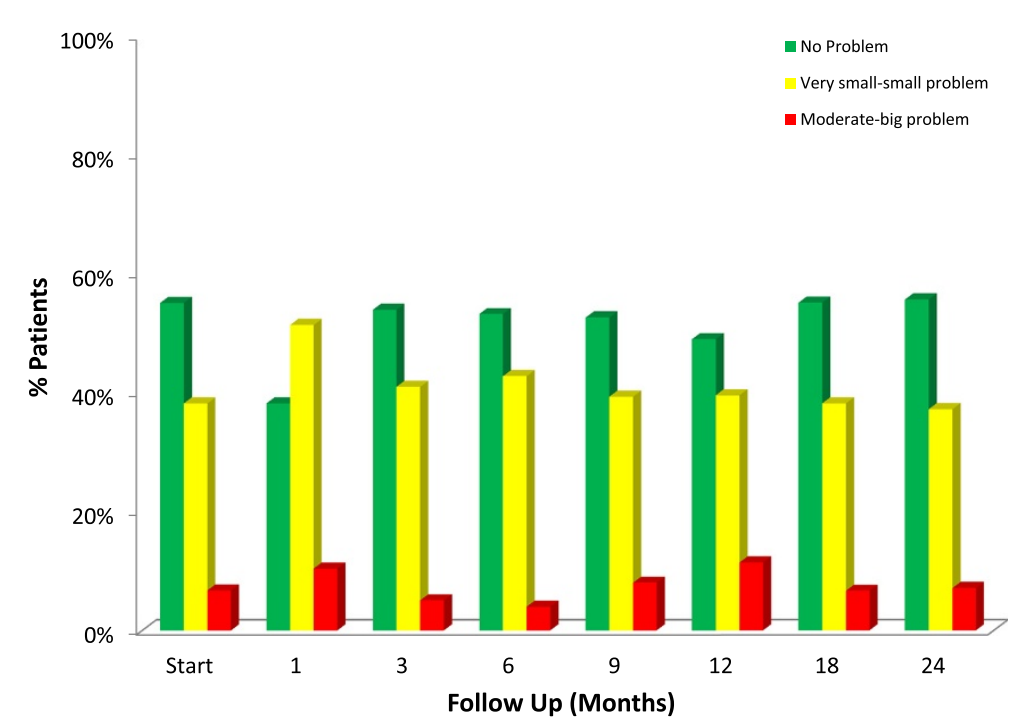

Figure 3 Bother with weak stream and/or incomplete emptying at baseline and following SBRT for prostate cancer, question 4d of the EPIC-26. Patients were stratified to three groups: no problem, very small to small problem and moderate to big problem. The percentage of patients in each group at each time point is depicted in the bar chart.

\section{Conclusions}

SBRT is a convenient treatment option for patients with clinically localized prostate cancer. Treatment resulted in an acute increase in obstructive urinary symptoms which peaked within the first month post-SBRT. These symptoms returned to baseline in the majority of patients by 6 months and in $>90 \%$ by 2 years. The risk of acute urinary retention requiring catheterization was low, and late increases in obstructive voiding symptoms were common, though transient. Overall, bother with obstructive voiding symptoms was at baseline two years post SBRT.

\section{Abbreviations}

ADT: Androgen deprivation therapy; AUR: Acute urinary retention; BED: Biologically effective dose; BPH: Benign prostatic hyperplasia; CT: Computed tomography; CTV: Clinical target volume; DVH: Dose-volume histogram; EQD2: Equivalent dose in 2-Gy fractions; EPIC: Expanded Prostate Index Composite; GTV: Gross target volume; Gy: Gray; IMRT: Intensity modulated radiation therapy; IPSS: International Prostate Symptom Score; IRB: Internal Review Board; PTV: Planning target volume; QoL: Quality of life; MID: Minimally important difference; MR: Magnetic resonance; SD: Standard deviation; SBRT: Stereotactic body radiation therapy; UI: Urinary incontinence; UR: Urinary retention.

\section{Competing interests}

SP Collins and BT Collins serve as clinical consultants to Accuray Inc. The Department of Radiation Medicine at Georgetown University Hospital receives a grant from Accuray to support a research coordinator. The other authors declare that they have no competing interests.

\section{Authors' contributions}

WA and LC are lead authors who participated in manuscript drafting, table/ figure creation, and manuscript revision. JW, JP, JK, RM, and TY aided in data collection and table/figure creation. SL is the dosimetrist who contributed dosimetric data and figures. SL, BC, KK, SS, AD, and JL are senior authors who aided in drafting the manuscript and manuscript revision. SC is the corresponding author who initially developed the concept, and drafted and revised the manuscript. All authors read and approved the final manuscript.

\section{Acknowledgements}

This work was supported by the James and Theodore Pedas Family Foundation and NIH Grant P30CA051008.

\section{Author details}

${ }^{1}$ Department of Radiation Medicine, Georgetown University Hospital, 3800 Reservoir Road, NW, Washington, DC 20007, USA. '2Department of Urology, Georgetown University Hospital, 3800 Reservoir Road, NW, Washington, DC 20007, USA.

Received: 5 March 2014 Accepted: 17 July 2014

Published: 24 July 2014

\section{References}

1. Sarma AV, Wei JT: Clinical practice. Benign prostatic hyperplasia and lower urinary tract symptoms. N Engl J Med 2012, 367:248-257.

2. Barry MJ, Fowler FJ Jr, O'Leary MP, Bruskewitz RC, Holtgrewe HL, Mebust WK, Cockett AT: The American Urological Association symptom index for benign prostatic hyperplasia. The Measurement Committee of the American Urological Association. J Urol 1992, 148:1549-1557. discussion 1564.

3. Chute CG, Panser LA, Girman CJ, Oesterling JE, Guess HA, Jacobsen SJ, Lieber MM: The prevalence of prostatism: a population-based survey of urinary symptoms. J Urol 1993, 150:85-89.

4. Platz EA, Joshu CE, Mondul AM, Peskoe SB, Willett WC, Giovannucci E: Incidence and progression of lower urinary tract symptoms in a large prospective cohort of United States men. J Urol 2012, 188:496-501.

5. Kristal AR, Arnold KB, Schenk JM, Neuhouser ML, Weiss N, Goodman P, Antvelink CM, Penson DF, Thompson IM: Race/ethnicity, obesity, health related behaviors and the risk of symptomatic benign prostatic hyperplasia: results from the prostate cancer prevention trial. J Urol 2007, 177:1395-1400. quiz 1591.

6. Sarma AV, St Sauver JL, Hollingsworth JM, Jacobson DJ, McGree ME, Dunn RL, Lieber MM, Jacobsen SJ: Diabetes treatment and progression of benign prostatic hyperplasia in community-dwelling black and white men. Urology 2012, 79:102-108.

7. Sanda MG, Dunn RL, Michalski J, Sandler HM, Northouse L, Hembroff L, Lin X, Greenfield TK, Litwin MS, Saigal CS, Mahadevan A, Klein E, Kibel A, Pisters LL, Kuban D, Kaplan I, Wood D, Ciezki J, Shah N, Wei JT: Quality of life and 
satisfaction with outcome among prostate-cancer survivors. N Engl J Med 2008, 358:1250-1261.

8. Hoppe BS, Michalski JM, Mendenhall NP, Morris CG, Henderson RH, Nichols RC, Mendenhall WM, Williams CR, Regan MM, Chipman JJ, Crociani CM, Sandler HM, Sanda MG, Hamstra DA: Comparative effectiveness study of patient-reported outcomes after proton therapy or intensity-modulated radiotherapy for prostate cancer. Cancer 2014, 120:1076-1082.

9. King BL, Butler WM, Merrick GS, Kurko BS, Reed JL, Murray BC, Wallner KE: Electromagnetic transponders indicate prostate size increase followed by decrease during the course of external beam radiation therapy. Int $J$ Radiat Oncol Biol Phys 2011, 79:1350-1357.

10. Waterman FM, Yue N, Corn BW, Dicker AP: Edema associated with I-125 or Pd-103 prostate brachytherapy and its impact on post-implant dosimetry: an analysis based on serial CT acquisition. Int J Radiat Oncol Biol Phys 1998, 41:1069-1077.

11. Bucci J, Morris WJ, Keyes M, Spadinger I, Sidhu S, Moravan V: Predictive factors of urinary retention following prostate brachytherapy. Int J Radiat Oncol Biol Phys 2002, 53:91-98.

12. Ghadjar $\mathrm{P}$, Jackson A, Spratt DE, Oh JH, Munck Af Rosenschold P, Kollmeier M, Yorke E, Hunt M, Deasy JO, Zelefsky MJ: Patterns and Predictors of Amelioration of Genitourinary Toxicity After High-dose Intensity-modulated Radiation Therapy for Localized Prostate Cancer: Implications for Defining Postradiotherapy Urinary Toxicity. Eur Urol 2013, 64(6):931-938.

13. Merrick GS, Butler WM, Lief JH, Dorsey AT: Temporal resolution of urinary morbidity following prostate brachytherapy. Int J Radiat Oncol Biol Phys 2000, 47:121-128.

14. Crook J, McLean M, Catton C, Yeung I, Tsihlias J, Pintilie M: Factors influencing risk of acute urinary retention after TRUS-guided permanent prostate seed implantation. Int J Radiat Oncol Biol Phys 2002, 52:453-460.

15. Litwin MS, Gore JL, Kwan L, Brandeis JM, Lee SP, Withers HR, Reiter RE: Quality of life after surgery, external beam irradiation, or brachytherapy for early-stage prostate cancer. Cancer 2007, 109:2239-2247.

16. Henderson A, Ismail AK, Cunningham M, Aldridge S, Loverock L, Langley SE, Laing RW: Toxicity and early biochemical outcomes from 125 iodine prostate brachytherapy in the UK. A prospective study. Clin Oncol (R Coll Radiol) 2004, 16:95-104.

17. Keyes M, Miller S, Moravan V, Pickles T, McKenzie M, Pai H, Liu M, Kwan W, Agranovich A, Spadinger I, Lapointe V, Halperin R, Morris WJ: Predictive factors for acute and late urinary toxicity after permanent prostate brachytherapy: long-term outcome in 712 consecutive patients. Int J Radiat Oncol Biol Phys 2009, 73:1023-1032.

18. Malik $R$, Jani $A B$, Liauw SL: External beam radiotherapy for prostate cancer: urinary outcomes for men with high International Prostate Symptom Scores (IPSS). Int J Radiat Oncol Biol Phys 2011, 80:1080-1086.

19. Terk MD, Stock RG, Stone NN: Identification of patients at increased risk for prolonged urinary retention following radioactive seed implantation of the prostate. J Urol 1998, 160:1379-1382.

20. Roeloffzen EM, Monninkhof EM, Battermann JJ, van Roermund JG, Moerland MA, van Vulpen M: Acute urinary retention after I-125 prostate brachytherapy in relation to dose in different regions of the prostate. Int J Radiat Oncol Biol Phys 2011, 80:76-84.

21. Devisetty K, Zorn KC, Katz MH, Jani AB, Liauw SL: External beam radiation therapy after transurethral resection of the prostate: a report on acute and late genitourinary toxicity. Int J Radiat Oncol Biol Phys 2010, 77:1060-1065.

22. Roeloffzen EM, van Vulpen M, Battermann JJ, van Roermund JG Saibishkumar EP, Monninkhof EM: Pretreatment nomogram to predict the risk of acute urinary retention after $1-125$ prostate brachytherapy. Int $J$ Radiat Oncol Biol Phys 2011, 81:737-744

23. Merrick GS, Butler WM, Wallner KE, Murray B, Allen Z, Lief JH, Galbreath RW: The effect of hormonal manipulation on urinary function following permanent prostate brachytherapy. Brachytherapy 2004, 3:22-29.

24. Stone NN, Marshall DT, Stone JJ, Cesaretti JA, Stock RG: Does neoadjuvant hormonal therapy improve urinary function when given to men with large prostates undergoing prostate brachytherapy? J Urol 2010, 183:634-639.

25. Elshaikh MA, Ulchaker JC, Reddy CA, Angermeier KW, Klein EA, Chehade N, Altman A, Ciezki JP: Prophylactic tamsulosin (Flomax) in patients undergoing prostate $125 \mathrm{I}$ brachytherapy for prostate carcinoma: final report of a double-blind placebo-controlled randomized study. Int J Radiat Oncol Biol Phys 2005, 62:164-169.

26. Prosnitz RG, Schneider L, Manola J, Rocha S, Loffredo M, Lopes L, D'Amico $A V$ : Tamsulosin palliates radiation-induced urethritis in patients with prostate cancer: results of a pilot study. Int J Radiat Oncol Biol Phys 1999, 45:563-566.

27. Brachman DG, Thomas T, Hilbe J, Beyer DC: Failure-free survival following brachytherapy alone or external beam irradiation alone for T1-2 prostate tumors in 2222 patients: results from a single practice. Int J Radiat Oncol Biol Phys 2000, 48:111-117.

28. Potters L, Morgenstern C, Calugaru E, Fearn P, Jassal A, Presser J, Mullen E: 12-year outcomes following permanent prostate brachytherapy in patients with clinically localized prostate cancer. J Uro/ 2005, 173:1562-1566.

29. Zelefsky MJ, Hollister T, Raben A, Matthews S, Wallner KE: Five-year biochemical outcome and toxicity with transperineal $C T$-planned permanent I-125 prostate implantation for patients with localized prostate cancer. Int J Radiat Oncol Biol Phys 2000, 47:1261-1266.

30. Crook J, Borg J, Evans A, Toi A, Saibishkumar EP, Fung S, Ma C: 10-year experience with I-125 prostate brachytherapy at the Princess Margaret Hospital: results for 1,100 patients. Int J Radiat Oncol Biol Phys 2011, 80:1323-1329.

31. Chan EK, Keyes M, Pickles T, Lapointe V, Spadinger I, McKenzie M, Morris WJ: Decline in acute urinary toxicity: a long-term study in 2011 patients with prostate brachytherapy within a provincial institution. Brachytherapy 2013, 13:46-52.

32. Keyes M, Schellenberg D, Moravan V, McKenzie M, Agranovich A, Pickles T, Wu J, Liu M, Bucci J, Morris WJ: Decline in urinary retention incidence in 805 patients after prostate brachytherapy: the effect of learning curve? Int J Radiat Oncol Biol Phys 2006, 64:825-834

33. Herstein A, Wallner $K$, Merrick G, Mitsuyama $H$, Armstrong J, True L, Cavanagh W, Butler W: I-125 versus Pd-103 for low-risk prostate cancer: long-term morbidity outcomes from a prospective randomized multicenter controlled trial. Cancer J 2005, 11:385-389.

34. Kollmeier MA, Pei X, Algur E, Yamada Y, Cox BW, Cohen GN, Zaider M, Zelefsky MJ: A comparison of the impact of isotope ((125) I vs. (103) Pd) on toxicity and biochemical outcome after interstitial brachytherapy and external beam radiation therapy for clinically localized prostate cancer. Brachytherapy 2012, 11:271-276.

35. Eapen L, Kayser C, Deshaies Y, Perry G, E C, Morash C, Cygler JE, Wilkins D, Dahrouge S: Correlating the degree of needle trauma during prostate brachytherapy and the development of acute urinary toxicity. Int J Radiat Oncol Biol Phys 2004, 59:1392-1394.

36. Buskirk SJ, Pinkstaff DM, Petrou SP, Wehle MJ, Broderick GA, Young PR, Weigand SD, O'Brien PC, Igel TC: Acute urinary retention after transperineal template-guided prostate biopsy. Int J Radiat Oncol Biol Phys 2004, 59:1360-1366.

37. Mock S, Leapman M, Stock RG, Hall SJ, Stone NN: Risk of urinary incontinence following post-brachytherapy transurethral resection of the prostate and correlation with clinical and treatment parameters. J Urol 2013, 190:1805-1810

38. Zelefsky MJ, Yamada Y, Marion C, Sim S, Cohen G, Ben-Porat L, Silvern D, Zaider M: Improved conformality and decreased toxicity with intraoperative computer-optimized transperineal ultrasound-guided prostate brachytherapy. Int J Radiat Oncol Biol Phys 2003, 55:956-963.

39. Albert M, Tempany CM, Schultz D, Chen MH, Cormack RA, Kumar S, Hurwitz MD, Beard C, Tuncali K, O'Leary M, Topulos GP, Valentine K, Lopes L, Kanan A, Kacher D, Rosato J, Kooy H, Jolesz F, Carr-Locke DL, Richie JP, D'Amico AV: Late genitourinary and gastrointestinal toxicity after magnetic resonance image-guided prostate brachytherapy with or without neoadjuvant external beam radiation therapy. Cancer 2003, 98:949-954.

40. Roeloffzen EM, Hinnen KA, Battermann JJ, Monninkhof EM, van Roermund JG, van Gellekom MP, Frank SJ, van Vulpen M: The impact of acute urinary retention after iodine-125 prostate brachytherapy on health-related quality of life. Int J Radiat Oncol Biol Phys 2010, 77:1322-1328.

41. McBride SM, Wong DS, Dombrowski JJ, Harkins B, Tapella P, Hanscom HN, Collins SP, Kaplan ID: Hypofractionated stereotactic body radiotherapy in low-risk prostate adenocarcinoma: Preliminary results of a multi-institutional phase 1 feasibility trial. Cancer 2012, 118:3681-3690.

42. Freeman DE, King CR: Stereotactic body radiotherapy for low-risk prostate cancer: five-year outcomes. Radiat Oncol 2011, 6:3.

43. Katz AJ, Santoro M, Diblasio F, Ashley R: Stereotactic body radiotherapy for localized prostate cancer: disease control and quality of life at 6 years. Radiat Oncol 2013, 8:118.

44. King CR, Collins S, Fuller D, Wang PC, Kupelian P, Steinberg M, Katz A: Health-related quality of life after stereotactic body radiation therapy for 
localized prostate cancer: results from a multi-institutional consortium of prospective trials. Int J Radiat Oncol Biol Phys 2013, 87:939-945.

45. King CR, Freeman D, Kaplan I, Fuller D, Bolzicco G, Collins S, Meier R, Wang J, Kupelian P, Steinberg M, Katz A: Stereotactic body radiotherapy for localized prostate cancer: pooled analysis from a multi-institutional consortium of prospective phase II trials. Radiother Oncol 2013, 109:217-221.

46. Fowler JF: The radiobiology of prostate cancer including new aspects of fractionated radiotherapy. Acta Oncol 2005, 44:265-276.

47. Chen LN, Suy S, Uhm S, Oermann EK, Ju AW, Chen V, Hanscom HN, Laing S, Kim JS, Lei S, Batipps GP, Kowalczyk K, Bandi G, Pahira J, McGeagh KG, Collins BT, Krishnan P, Dawson NA, Taylor KL, Dritschilo A, Lynch JH, Collins SP: Stereotactic body radiation therapy (SBRT) for clinically localized prostate cancer: the Georgetown University experience. Radiat Oncol 2013, 8:58,

48. Lei S, Piel N, Oermann EK, Chen V, Ju AW, Dahal KN, Hanscom HN, Kim JS, Yu X, Zhang G, Collins BT, Jha R, Dritschilo A, Suy S, Collins SP: Six-dimensional correction of intra-fractional prostate Motion with CyberKnife stereotactic body radiation therapy. Front Oncol 2011, 1:48

49. Vainshtein J, Abu-Isa E, Olson KB, Ray ME, Sandler HM, Normolle D, Litzenberg DW, Masi K, Pan C, Hamstra DA: Randomized phase II trial of urethral sparing intensity modulated radiation therapy in low-risk prostate cancer: implications for focal therapy. Radiat Oncol 2012, 7:82.

50. Xie Y, Djajaputra D, King CR, Hossain S, Ma L, Xing L: Intrafractional motion of the prostate during hypofractionated radiotherapy. Int I Radiat Oncol Biol Phys 2008, 72:236-246.

51. Helfand BT, Fought A, Manvar AM, McVary KT: Determining the utility of recalled lower urinary tract symptoms. Urology 2010, 76:442-447.

52. Barry MJ, Williford WO, Fowler FJ Jr, Jones KM, Lepor H: Filling and voiding symptoms in the American Urological Association symptom index: the value of their distinction in a Veterans Affairs randomized trial of medical therapy in men with a clinical diagnosis of benign prostatic hyperplasia. J Urol 2000, 164:1559-1564.

53. Wei JT, Dunn RL, Litwin MS, Sandler HM, Sanda MG: Development and validation of the expanded prostate cancer index composite (EPIC) for comprehensive assessment of health-related quality of life in men with prostate cancer. Urology 2000, 56:899-905.

54. Norman GR, Sloan JA, Wyrwich KW: Interpretation of changes in health-related quality of life: the remarkable universality of half a standard deviation. Med Care 2003, 41:582-592.

55. Symon Z, Daignault S, Symon R, Dunn RL, Sanda MG, Sandler HM: Measuring patients' expectations regarding health-related quality-of-life outcomes associated with prostate cancer surgery or radiotherapy. Urology 2006, 68:1224-1229.

56. Pollack A, Walker G, Horwitz EM, Price R, Feigenberg S, Konski AA, Stoyanova R, Movsas B, Greenberg RE, Uzzo RG, Ma C, Buyyounouski MK: Randomized trial of hypofractionated external-beam radiotherapy for prostate cancer. J Clin Oncol 2013, 31:3860-3868.

57. Merrick GS, Butler WM, Wallner KE, Lief JH, Galbreath RW: Prophylactic versus therapeutic alpha-blockers after permanent prostate brachytherapy. Urology 2002, 60:650-655.

58. King CR, Brooks JD, Gill H, Pawlicki T, Cotrutz C, Presti JC Jr: Stereotactic body radiotherapy for localized prostate cancer: interim results of a prospective phase II clinical trial. Int I Radiat Oncol Biol Phys 2009, 73:1043-1048.

59. Cesaretti JA, Stone NN, Stock RG: Urinary symptom flare following I-125 prostate brachytherapy. Int J Radiat Oncol Biol Phys 2003, 56:1085-1092.

60. Crook J, Fleshner N, Roberts C, Pond G: Long-term urinary sequelae following 125iodine prostate brachytherapy. J Urol 2008, 179:141-145. discussion 146.

61. Keyes M, Miller S, Moravan V, Pickles T, Liu M, Spadinger I, Lapointe V, Morris WJ: Urinary symptom flare in 712125 l prostate brachytherapy patients: long-term follow-up. Int J Radiat Oncol Biol Phys 2009, 75:649-655.

62. Gore JL, Gollapudi K, Bergman J, Kwan L, Krupski TL, Litwin MS: Correlates of bother following treatment for clinically localized prostate cancer. J Urol 2010, 184:1309-1315.

\section{doi:10.1186/1748-717X-9-163}

Cite this article as: Arscott et al: Obstructive voiding symptoms following stereotactic body radiation therapy for prostate cancer. Radiation Oncology 2014 9:163.

\section{Submit your next manuscript to BioMed Central and take full advantage of:}

- Convenient online submission

- Thorough peer review

- No space constraints or color figure charges

- Immediate publication on acceptance

- Inclusion in PubMed, CAS, Scopus and Google Scholar

- Research which is freely available for redistribution 